\title{
УДК 331.438+613.6.02+355
}

\section{ПРОФЕССИОНААЬНАЯ АЕЯТЕАЬНОСТЬ В ЭКСТРЕМАЯЬНЫХ УСАОВИЯХ СРЕАЫ: OПPЕАЕАЕНИЕ, КААССИФИКАUИЯ}

\section{Кальниш В. $\mathbf{B}$.}

\author{
Государственное учрежАение «Институт мехицины труда Нашиональной академии \\ медишинских наук Украины», г. Киев
}

Введение. Исследование влияния экстремальных условий деятельности на состояние здоровья и успешность труда человека в настоящее время получило новый импульс, появление которого связано с усложнением техники, возникновением новых опасных видов профессиональной деятельности, повсеместным использованием устаревшего оборудования, а также многих других факторов, формирующих современные проблемы в медицине труда.

Цель исследования - структурировать сведения о влиянии на организм работника факторов экстремальных условий среды и установить вероятные подходы, позволяющие организму компенсировать их вредное действие.

Материалы и методы исследования. Проведен анализ и обобщение данных литературы по вопросам влияния экстремальных условий труда на организм человека.

Результаты. В результате анализа данных литературы предложена классификация условий и/или ситуаций, формирующих стресс у человека, работающего в условиях с повышенной опасностью. Предложен подход, в котором на основе механизма стихийного отбора осуществляется селекция лиц, способных работать в этих условиях путем формирования специальной функциональной системы, которую можно назвать психофизиологическим «панцирем».

Bыводы. Проведена структуризация экстремальных факторов трудовой среды, позволяющая выделить наиболее значимые из них и определить их место в системе действующих на человека раздражителей. Сформулирована гипотеза о возможном механизме «естественного отбора» под действием комплекса экстремальных факторов, позволяющем оставить на работе тех лиц, у которых возможно формирование защитного психофизиологического «панциря», способствующего их устойчивости к преодолению имеющихся испытаний.

Ключевые слова: экстремальные условия деятельности, опасные условия труда, классификация факторов среды, психоэмоциональное напряжение

\section{Введение}

Исследование влияния экстремальных условий деятельности на состояние здоровья и успешность труда человека в настоящее время получило новый импульс, появление которого связано с усложнением техники, возникновением новых опасных видов профессиональной деятельности, повсеместным использованием устаревшего оборудования, а также многих других факторов, формирующих современные проблемы в медицине труда. Эти проблемы особенно остро дают о себе знать в период проведения в нашей стране коренных социально-экономических преобразований, сопровождающихся кризисами и даже локальными боевыми конфликтами [13, 27, 39, 42].

Цель исследования - структурировать сведения о влиянии на организм работника факторов экстремальных условий среды и установить вероятные подходы, позволяющие организму компенсировать их вредное действие.

\section{Материалы и методы исследования}

Проведен анализ и обобщение данных литературы по вопросам влияния экстремальных условий труда на организм человека. Исследования, проведенные многими авторами, показали, что последствием влияния экстремальных ситуаций нередко является формирование у человека психогенных расстройств $[2,5,7,20]$ и расстройств пограничного уровня различной этиологии [34]. Такое положение дел связано с тем, что человек, пребывающий в условиях действия экстремальных факторов среды, должен перманентно, с помощью значительных волевых усилий преодолевать их вредное воздействие, активно бороться с последствиями наличных стрессовых реакций $[20,29]$. Физиологическая стоимость таких усилий весьма высока, что в итоге может привести к нарушению психического здоровья. Например, существуют прогнозы, что в ходе возможной войны на Европейском театре от 25 до 50 \% личного состава вооруженных сил могут потерять 
боеспособность в результате формирования значительного уровня стресса [43].

Изучением воздействия экстремальных условий занималось ряд авторов, среди которых можно особо отметить В. Д. Небылицина, Б. Ф. Ломова, Л. А. Қитаева-Смыка, Н. И. Наенко, А. Г. Кузнецова и др. [9, 16, 17, 21, 25, 35-37]. Было показано, что в результате работы в этих условиях у лиц, наряду с высоким риском травматизма или утраты здоровья, наблюдается повышение нервно-эмоционального напряжения и снижение функциональных резервов организма $[4,10,40]$. Действие указанных условий способствует развитию определенных «непсихотических расстройств» $[45,49]$. Нередко они провоцируют появление медико-социальных последствий, а именно: увеличение числа заболеваний психогенной природы, учащение и усложнение клинических проявлений посттравматических стрессовых расстройств, увеличение числа случаев злоупотребления алкоголем и наркотиками, возникновение семейных конфликтов, нарастание числа случаев агрессивных реакций, суицидального поведения и пр. [50].

В результате многочисленных исследований было выделено достаточно большое количество характеристик, которые могут быть стрессорами в условиях профессиональной деятельности с повышенной опасностью. В. А. Бодров разделил их на шесть групп: профессиональные требования и характеристики поставленных задач; ролевые требования или ожидания; организационные требования; внешние требования или условия; стресс возможности (возможности что-то приобрести); стресс ограничения в достижении (чего-то желаемого) [8]. Однако в этой классификации все пункты носят слишком обобщенный характер и не охватывают основные вероятные причины возникновения стрессовых реакций в результате деятельности в опасных условиях. Поэтому актуальность исследования деятельности в экстремальных условиях среды не вызывает сомнений.

\section{Результаты исследования и их обсуждение}

Существует целый ряд обозначений экстремальных условий деятельности. Наряду с термином «экстремальные», часто используются другие названия этого понятия. В частности, достаточно широко распространены такие обозначения, как «особые», «трудные», «крайние», «критические», «эмоциогенные», «сложные», «аварийные», «чрезвычайные», «сверхэкстремальные», «гиперстрессовые». Однако, по существу, все они имеют близкую по своей природе смысловую нагрузку. Экстремальные условия деятельности могут рассматриваться как такие условия, при которых внезапно возникают или постоянно действуют обстоятельства, угрожающие или субъективно воспринимающиеся человеком как угрожающие его жизни, здоровью, личной целостности или благополучию. В деятельности работников «опасных профессий» существуют два типа обстоятельств, при которых труд может считаться экстремальным [12]:

1 ) при осуществлении повседневной напряженной деятельности, в условиях которой опасность представлена как потенциально возможные и «вредные» по своей природе события, находящиеся за пределами обычного опыта человека, способствующие разрушению стереотипных, нормативных схем взаимоотношений и провоцирующие устойчивое избегание стимулов, характеризующих это событие;

2 ) при появлении и развитии неожиданных «критических» инцидентов или ситуаций, стимулирующих развитие устойчивых симптомов повышенного возбуждения, при которых работники сталкиваются с человеческими жертвами и/или существенными материальными потерями, с реальной опасностью для своей жизни, здоровью или системы ценностей, а также с угрозой жизни, здоровью, благополучию окружающих.

Таким образом, несмотря на сходство понятий, экстремальные условия несколько отличаются от экстремальных ситуаций. Если экстремальные условия можно отождествлять с «критическими» обстоятельствами, которые незначительно изменяются во времени, то экстремальные ситуации развиваются за короткий промежуток времени и характеризуются резкими динамичными изменениями обстоятельств деятельности.

Целесообразно также отдельно обсудить вопрос о различии понятий экстремальные факторы и экстремальные условия. Первые предполагают воздействие отдельного фактора: физического, психологического или иного происхождения. Экстремальные условия охватывают более обширную область воздействий, включающих влияние нескольких или многих факторов. В этом случае интегральный результат их влияния на организм человека имеет более сложный, вероят- 
ностный характер, так как совместное действие определенного количества факторов может оказывать на организм человека различный эффект в зависимости от конкретного сочетания этих факторов.

Необходимо отметить, что уровень «экстремальности» ситуации или условий может быть разным, а также непостоянным во времени. Например, некоторые авторы считают, что условия деятельности могут быть «трудными», «параэкстремальными» и «экстремальными» [36]. Другие учитывают постепенное усложнение «экстремальности» и добавляют еще одну категорию - «паратерминальные» условия [30]. Военные психологи считают, что в классификацию экстремальных условий следует ввести параметр уровня мобилизации «буферных», а в усложненном случае «аварийных» резервов организма [9].

Вероятно, что все указанные особенности необходимо учитывать при оценке экстремальности ситуаций или условий деятельности. Но в действую щих нормативных документах такая дифференциация экстремальных условий в полной мере не предусмотрена. Так, в действующей «Гигиенической классификации труда ...» (2014 г.) не предусмотрено использование терминов «экстремальные» или «особые» условия труда. Вместо этих терминов в ней определены близкие по смыслу к перечисленным характеристикам - «опасные» условия труда. Причем под опасными условиями труда подразумеваются условия, которые характеризуются такими уровнями вредных факторов производственной среды и трудового процесса, влияние которых в течение рабочей смены (или ее части) создают угрозу для жизни, высокий риск формирования острых профессиональных поражений, в том числе и тяжелых форм. К сожалению, термины «угроза» и «высокий риск» не уточняются. Следовательно, определить степень «угрозы» или «риска» по этой классификации весьма затруднительно.

В ДСТУ 2293-93 дано определение вредного производственного фактора: «производственный фактор, воздействие которого в определенных условиях может привести к заболеванию, снижению работоспособности и (или) отрицательному влиянию на здоровье потомства». В этом документе также приводится определение производственного риска, как «вероятности повреждения здоровья работника при исполнении им трудовых обязанностей, обусловленной степенью вредности и (или) опасности условий труда и научно-техническим состоянием производства».

Таким образом, триада понятий: опасные условия труда, вредный производственный фактор и производственный риск, по-видимому, могут в достаточной степени полно охарактеризовать действие на организм человека комплекса экстремальных факторов.

Определенные факторы трудовой среды могут проявляться в виде различного по величине и качеству воздействия на конкретного человека. Так, например, определенное влияние на переносимость экстремальных условий деятельности оказывают психологические и психофизиологические качества организма работника. Экспериментальные данные, полученные при моделировании деятельности в экстремальных условиях, показывают наибольшую значимость силы нервных процессов, их подвижности по параметру торможения, уровня невротизации и эмоциональной стабильности [39]. У лиц с лучшими характеристиками этих качеств наблюдалась более быстрая адаптация, высшая степень успеваемости при обучении, высокая психологическая устойчивость.

Дополнительно следует обратить внимание на тот факт, что экстремальные условия деятельности не только отрицательно влияют на организм человека, но и имеют определенную положительную сторону. В частности, участие в боевых действиях способствует формированию у человека таких качеств, как решительность, инициативность, ловкость, способность к самостоятельной выработке адекватных решений, так как в этих условиях выживает именно тот, кто в большей мере обладает такими ценными качествами [33].

Степень опасности условий труда определяется длительностью, частотой и интенсивностью вредных производственных факторов, которые могут иметь «внешнее» и «внутреннее» происхождение (рисунок). К внешним факторам можно отнести: факторы трудовой деятельности, а также физические, химические, биологические и экономические факторы.

Если влияние физических, химических и биологических факторов подробно анализируется в литературе по гигиене труда, то экономические факторы, имеющие социально-психологическую природу, изучены меньше и их обсуждение в медицинской литературе не так популярно. Они должны учитывать такие экономические характеристики, которые 


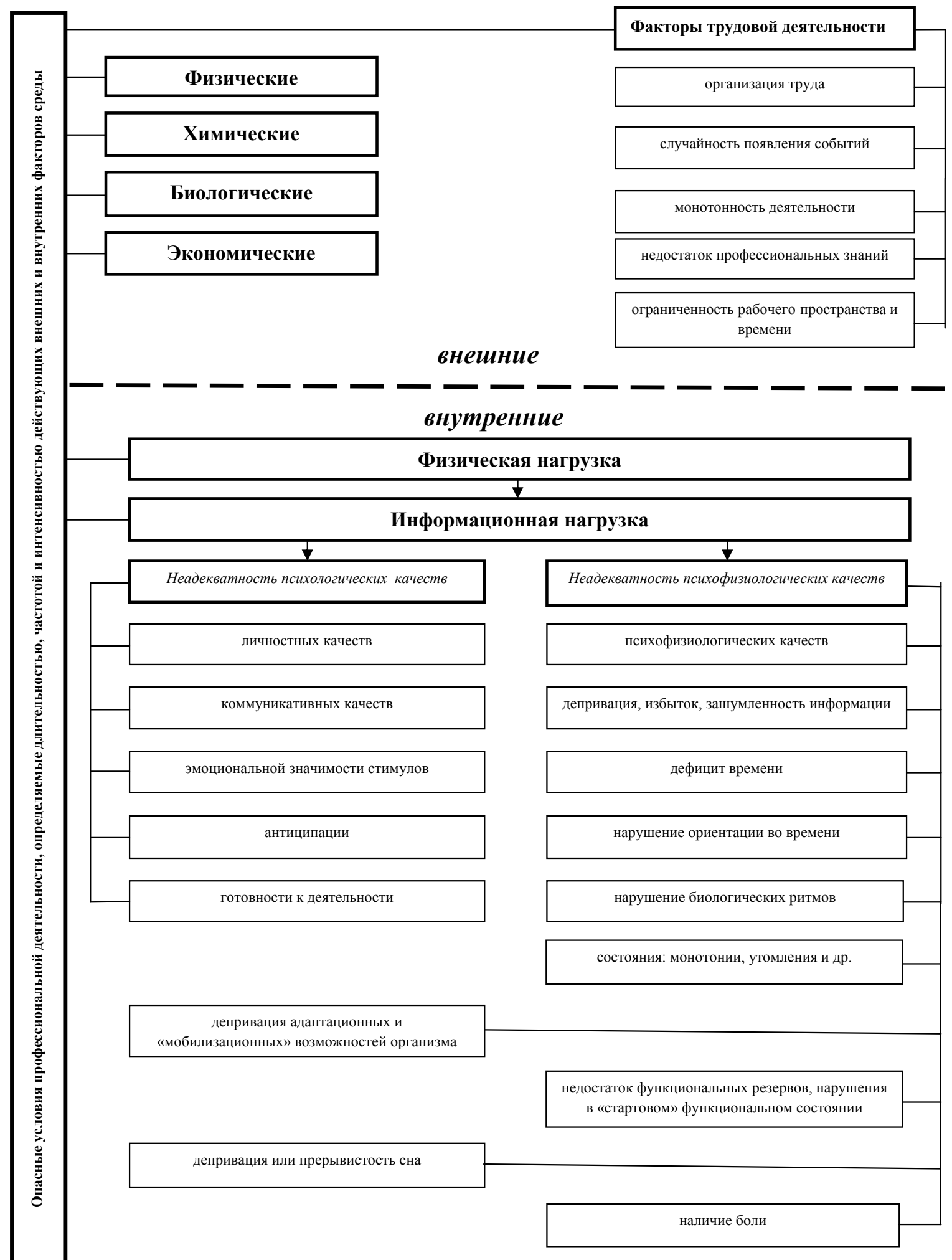

Рисунок. Структурная схема действия на организм работающего человека экстремальных факторов трудовой среды 
влияют на психоэмоциональное напряжение работника, но связаны с экономическим состоянием человека и общества. К подобным факторам можно отнести: недостаточность оплаты труда, отсутствие четкости в оплате труда, несоответствие между затратой сил на выполнение работы и ее оплатой, наличие дополнительной работы за другого человека и другие факторы, значительно снижающие мотивацию к осуществлению профессиональной деятельности.

Особо следует остановиться на вредном действии факторов трудовой деятельности. Это, прежде всего, группа организационных факторов, регулируемых руководством предприятия или учреждения. К ним можно отнести фактор организации режима труда, обусловливающий длительность и частоту действия профессиональных нагрузок, включая сверхнормативные затраты времени работника; сменный характер деятельности; наличие периодов неудобного для работника времени осуществления профессиональной деятельности. Важными в этом плане также являются частое изменение служебных обязанностей, отсутствие необходимых условий для выполнения работы, нечетко очерченный круг обязанностей и прав работника, невозможность самостоятельного выбора рациональной стратегии деятельности, неудовлетворительная организация и содержание трудовой деятельности, связанная с перегрузками или недогрузками при выполнении работы. Значительно влияют на работоспособность плохое качество часто устаревшего оборудования и недостаток профессиональных знаний, умений, навыков, негативно сказывающийся на эффективности работы.

Существенно воздействует на человека такой фактор, как возможность возникновения случайных отклонений от технологического процесса, внезапных ситуаций при управлении машиной или динамичное изменение обстановки в условиях неопределенности. Здесь необходимо заметить, что любая профессиональная деятельность не обходится без появления таких ситуаций. Однако, если они очень редки и не имеют высокой интенсивности, то их появление существенным образом не сказывается на функциональном состоянии работника. Более того, их формирование способствует мобилизации возможностей специалиста. Приносящими ущерб организму являются очень интенсивные, длительные или частые неожиданные отклонения в работе оборудования.
Проявляющийся в некоторых случаях фактор однородности деятельности опасен по нескольким причинам. Во-первых, его специфическое воздействие на организм вызывает развитие особого состояния монотонии, которое характеризуется быстрым формированием сонливости, апатии и других неблагоприятных состояний $[19,20]$. Наличие такого состояния требует от работника дополнительных усилий по поддержанию организма на нужном уровне бодрствования и, следовательно, дополнительные затраты его функциональных резервов, особенно в режиме ожидания. Во-вторых, часто деятельность не является постоянно однородной на значительном промежутке времени. Монотонная работа сменяется спонтанно возникающей или запланированной сложной производственной ситуацией. В этом случае организму необходимо осуществлять срочную перестройку своих функциональных возможностей, что является большой энергозатратной задачей.

K перечню вредных можно также отнести еще целый ряд факторов трудовой среды. Так, следует обратить усиленное внимание на фактор ограниченности рабочего пространства, наличие которого существенно увеличивает степень воздействия на организм физических, химических и других вредных факторов. Ограниченное пространство вызывает у работников трудности не только физического плана, такие как изменение привычного способа действий, рабочей позы (продвижение ползком, работа в позе лежа и т. д.), но и психического [24]. Особенно опасным является то, что в период осуществления профессиональной деятельности у этих сотрудников наблюдается смещение фокуса внимания на свое собственное состояние. Это приводит к значительному снижению надежности деятельности, а иногда и к отказу от выполнения работы.

Естественно, трудно кратко и достаточно полно описать исчерпывающее число внешних факторов, формирующих опасные условия профессиональной деятельности. В известной степени очевидным становится тот факт, что действие любого внешнего фактора или ряда факторов коренным образом отражается на функциональном состоянии человека и тем самым формирует его работоспособность.

Но, кроме внешних факторов, объективно существует еще целый ряд внутренних факторов, которые в зависимости от индивидуальной чувствительности организма человека вырабатывают ответные реакции его организма на действие вредных условий 
трудовой среды. Взаимная индукция действующих внешних и внутренних факторов, их уникальная композиция, которая пронизывает всю систему «человек-среда», формирует целостную картину действия на организм человека опасных условий профессиональной деятельности.

Комплекс внутренних факторов можно условно разделить на две категории, появляющиеся в результате реализации влияния на организм человека физических и информационных нагрузок. Но здесь уместно рассмотреть негативные реакции организма на трудовые нагрузки, сообразуясь с его чувствительностью и способностью адаптироваться к ним, возможностью качественно осуществлять профессиональную деятельность. В этом плане физическая нагрузка также в значительной своей части трансформируется в информационную нагрузку, поскольку механизмы управления двигательной активностью и сердечно-сосудистой системой, непосредственно обеспечивающие процесс выполнения физической работы, тоже вносят существенный вклад в формирование информационного компонента напряжения работы центральной нервной системы.

Информационные процессы, совершающиеся в организме работающего человека, также можно условно разделить на два класса: психологические и психофизиологические, затруднения в протекании которых ведет к росту рабочего напряжения. Неадекватность психологических качеств, прежде всего, ведет к снижению успешности работы и связана с комплексом личностных характеристик работающего индивидуума. Для каждой профессии могут быть выделены те личностные характеристики, которые способствуют или препятствуют качественному выполнению работы. Среди этих характеристик, прежде всего, целесообразно выделить ответственность, которая отражается на эффективности выполнения любой работы и влияет на уровень рабочего напряжения организма работника.

Важными также являются личностные качества, определяющие коммуникативные способности человека. Эти свойства обеспечивают возможность продуктивного содействия различных специалистов при коллективном выполнении работы, но их несовместимость может сильно повысить психоэмоциональное напряжение у членов микрогруппы, особенно в условиях, когда профессиональная деятельность является опасной. В этом случае можно особо выделить: конфликты личностных ценностей и ценностей, декларируемых коллективом организации; проблемы, связанные с тем, что работник должен работать не только на себя, но и выполнять «чужую» работу; определенное ограничение воли, связанное с существующими в коллективе интригами; изоляцию в рабочей группе; неадекватное отношение коллег; частые конфликты с руководством; неадекватный стиль управления руководства; сверхнормативные часы работы, которые приводят к проблемам в семье; негативное отношение к объектам и субъектам служебной деятельности и др.

Конечно, весь опыт изучения психических явлений в условиях профессиональной деятельности констатирует не строгую обязательность влияния определенных личностных качеств на ее эффективность, но, по-видимому, следует признать, что эмоциональная значимость стимулов трудовой среды играет ключевую роль в формировании воздействия этого компонента психики на самочувствие и здоровье работника. Эмоциональная значимость стимулов, определяемая чувствительностью человека к их появлению, влияет на его стрессоустойчивость и формирует соответствующую мотивацию для выполнения производственных заданий. Неадекватные для данного работника условия профессиональной деятельности, необходимость принимать большое число ответственных решений или отсутствие возможности принимать таковые развивают у него неудовлетворенность, чувство «заложника» выполняемой деятельности. А если такая работа соединена с внезапностью, непривычностью, неопределенностью или существенной новизной создаваемых ситуаций и может сопровождаться изоляцией от коллектива, недоверием к решениям, принятым руководством или другими референтными лицами, пребыванием работника в обстановке, связанной со страданием людей, то такое сочетание чрезвычайных раздражителей или их части может вызвать запредельную эмоциональную реакцию его организма, способствующую нарушению здоровья.

K экстремальным факторам психоэмоциональной природы можно также отнести: необходимость постоянной поддержки высокой психоэмоциональной волевой мобилизации, концентрации внимания, личную опасность для жизни и здоровья; ощущение, что ничего лучшего не найти; озабоченность возможным появлением ошибочных действий; необходимость параллельного принятия 
большого количества решений или, наоборот, малое участие в процессе принятия решений; высокая субъективная значимость ситуации.

Специфическими факторами, способствующими развитию особых психоэмоциональных состояний, например, при осуществлении военной деятельности, являются активные действия со стороны объектов противоборствующей стороны, постоянное ожидание негативных последствий при контакте с объектами противоборствующей стороны, необходимость применения оружия против объектов противоборствующей стороны, в том числе для физического уничтожения, реальная или возможная угроза жизни и здоровью, «биологический страх смерти», ни с чем не сравнимый стресс, который возникает у непосредственного участника боя, эмоциональный стресс, связанный с гибелью товарищей по оружию и др.

Важным фактором, влияющим на эффективность деятельности человека и на его психоэмоцио нальное напряжение, является фактор антиципации. В этом понятии определенным образом объединяются прошлые, настоящие и будущие события, поскольку антиципация есть способность принимать те или иные решения и действовать с определенным временно-пространственным упреждением в отношении ожидаемых событий [28]. Наличие такого свойства как антиципация, которая играет особенно большую роль в условиях с повышенной опасностью, способствует формированию чувства опасности, угрозы или обеспокоенности за последствия ошибочных действий. Антиципации присущи не только эффекты упреждения событий, но и избирательность средовых воздействий, направленность активности поведения [3]. Именно в этом смысле феномен антиципации имеет универсальное значение для всех форм человеческой деятельности. Поэтому еще И. П. Павлов ввел термин «предупредительная деятельность» - такая деятельность, которая способствует упреждению организма предстоящим событиям внешнего мира.

Қак указывают современные авторы, интуитивный выбор, обусловленный свойством антиципации, связан с ощущением настоящего и будущего, но имеет менее сильную связь с прошлым [11], так как наибольшее количество корреляционных связей обнаружено с оценками настоящего и ближайшего будущего. Причем, эмоционально позитивное окрашивание настоящего и будущего в какой-то мере нивелирует результаты предупреж- дения о предстоящей опасности и тем самым увеличивает время интуитивного прогноза появления «опасных» стимулов как нерелевантных актуальному состоянию человека. Наоборот, состояние повышенной бдительности, тревожного ожидания, наличие опыта преодоления опасных ситуаций нацеливает работу интуиции на выявление именно опасных ситуаций, что может быть весьма полезным при работе в условиях с повышенной опасностью.

Одним из значимых аспектов свойства антиципации есть готовность к деятельности - приведение в активное состояние всех психофизиологических систем человеческого организма, необходимых для исполнения определенных действий [41]. Состояние психологической готовности имеет сложную, динамично изменяющуюся структуру с включением интеллектуальных, эмоциональных и волевых сторон психики человека в их сцеплении с внешними условиями и будущим заданием. Авторы [14] приводят перечень взаимосвязанных психических компонентов, определяющих структуру готовности к деятельности, а именно: осознание потребностей (общества, коллектива, личных) или задания, поставленного другими людьми; осознание целей, решение которых приведет к удовлетворению потребностей или выполнению поставленного задания; осознание и оценка условий, в которых будут происходить будущие события; актуализация имеющегося опыта; оценивание на основе этого опыта будущих условий деятельности, наиболее вероятных и дополнительных способов решения задания; прогнозирование проявлений своих возможностей и необходимости достижения определенного результата; мобилизация сил относительно создавшихся условий и задания; самовнушение, направленное на достижение цели.

Среди факторов психофизиологической природы целесообразно обсудить несколько наиболее важных. Одним из таковых является фактор не соответствия конкретной профессии психодинамических и индивидуально-типологических качеств, которые можно объединить в группу психофизиологических качеств. Такие свойства ЦНС человека, как сила, функциональная подвижность, уравновешенность, динамичность, лабильность и другие играют первостепенную роль в обеспечении результативной деятельности в экстремальных условиях. Различные скоростные характеристики 
организма также подключаются при выполнении работ в сложных и аварийных ситуациях [15]. Немаловажными также являются свойства кратковременной памяти, внимания, мышления и другие.

Информационная нагрузка с одной стороны является свойством трудовой среды, а с другой ее восприятие и адекватная переработка в значительной степени зависит от возможностей организма человека. В любом случае недостаток, избыток или зашумленность поступающей информации в значительной мере затрудняют его деятельность и повышают психоэмоциональное напряжение организма работника.

Достаточно часто встречающимся, особенно в экстремальных ситуациях, является фактор дефицита времени. Его действие в значительной мере связано со свойствами организма работника, так как для одного человека определенный темп работы не является критичным, а для другого - ведет к существенным перегрузкам нервной и мышечной систем.

Для выполнения экстренной сложной работы необходимо иметь существенный запас функциональных адаптационных резервов организма. Его адаптационные резервы в общем виде представляют собой возможности отдельных систем и организма в целом противостоять воздействию различ ного вида вредных факторов, минимизируя их действие и тем самым обеспечивая должный уровень эффективности профессиональной деятельности [31]. Недостаток этих резервов приводит к быстрому изнашиванию соответствующих систем организма и понижает успешность деятельности человека. Кроме того, недостаток адаптивных и «мобилизационных» возможностей организма приводит к появлению ошибок, наличие которых в экстремальных ситуациях может привести к «печальным» последствиям, как при выполнении работы, так и в разрезе нанесения ущерба здоровью работника. Частными случаями, которые формируют временное или длительное снижения функциональных резервов организма, являются состояние монотонии, утомления, переутомления, хронического утомления и др. Каждому из этих состояний свойственно специфическое нарушение функциональных резервов организма, нормализация которых требует специальных медико-психологических процедур и продолжительного времени.

Значительное влияние на функциональное состояние человека при выполнении работ оказы- вает нарушение его биологических ритмов, которое происходит под действием ряда причин, в частности, связанных со спецификой развития экстремальных ситуаций. Одним из существенных последствий такого нарушения является недостаток или прерывистость сна, которые приводят к тяжелым последствиям при выполнении работ, связанных с повышенной опасностью [47]. Выраженность негативных эффектов хронической депривации сна у различных людей обладает высокой и стабильной индивидуальной вариабельностью, что предполагает вклад в нее генетических факторов [46]. В литературе констатируется, что при нарушении работы биологических часов разобщаются связи либо между местными осцилляторами, либо между центральным осциллятором и остальным организмом. Причем, эти нарушения лежат в основе дальнейшего развития десинхроноза нейроэндокринных ритмов и поведения, которые проявляются у здоровых, а, особенно, больных людей [22]. В частности, в результате анализа структуры суточных ритмов по психофизиологическим показателям двух групп операторов теплоэлектроцентрали, которые работали по графику с 12 -ч продолжительностью дневных и ночных смен, установлено, что у них в 39-93 \% случаев наблюдались нарушения фазовой структуры суточных ритмов [26]. У группы операторов с высокой напряженностью труда среднесуточные величины показателей были больше, а амплитуды суточных ритмов выше, чем у группы с более низкой напряженностью. Выраженная десинхронизация суточных ритмов явилась следствием влияния двух стрессогенных факторов - сменности и напряженности труда.

Нарушение ориентации во времени является одной из важных причин развития стресса при работе в условиях с повышенной опасностью. Неадекватная оценка временных интервалов в значительной степени зависит от содержания выполняемой человеком деятельности и условий ее реализации. Во всевозможных случаях нарушение такой оценки происходит по-разному: время «ускоряется» или «замедляется». В частности, при сильном волнении субъективно оцениваемое течение времени значительно ускоряется, несмотря на уверенность человека, что прошел именно нужный его интервал [38].

Воздействие экстремальных условий труда может привести к повреждению организма работ- 
ника, которое сопровождаются проявлениями боли и другими неприятными ощущениями. В этом случае заменить человека, выполняющего ответственную работу, не всегда представляется возможным. Вместе с тем, такие проявления могут существенно влиять на работоспособность и функциональное состояние человека, что повышает вероятность сбоев в его работе, способствует формированию экономических, экологических и социальных потерь.

Так, было установлено, что болевой синдром вызывает увеличение мощности спектра высокочастотной биоэлектрической активности коры головного мозга, снижение показателей памяти и внимания в раннем посттравматическом периоде, с сохранением умеренного когнитивного дефицита в позднем посттравматическом периоде [23]. Последствиями протекания хронического болезненного процесса могут стать нервно-психические перегрузки и, как следствие, нарушение психофизиологических функций [48]. Наряду с этим, значительно повышается психоэмоциональное напряжение человека, оказывающее влияние на успешность его трудовой деятельности. Например, среди сотрудников силовых структур с заболеваниями ЖКТ, у 92,9 \% из которых преобладал болевой синдром, наблюдалось значительное повышение психоэмоционального напряжения [6].

При возникновении ситуаций «борьбы за жизнь», что часто бывает при работе в экстремальных условиях, темп использования функциональных резервов для обеспечения жизнестойкости организма значительно возрастает, жизненный потенциал человека снижается, увеличивается функциональная стоимость производимой им работы, функциональные «потери» организма становятся невосполнимыми. В этих условиях, когда имеется высокий риск разрушения организма, его функционирование совершается в нестандартном режиме. Такой режим не может продолжаться достаточно долго без развития определенных серьезных патологий или смерти человека.

Спецификой деятельности лиц, работающих в опасных условиях среды, является их постоянное пребывание под действием фактора риска, влияние которого усугубляется выполнением заданий в условиях неопределенности, дефицитом информации и времени, высокой ответственностью за предпринятые действия [44]. Поэтому поведенческие реакции работников, в частности, военнослужа- щих, имеющих повышенную психическую нагрузку, сопровождаются сильными эмоциональными переживаниями, повышением физиологической стоимости деятельности, разбалансировкой функционирования управляющих систем организма, снижением работоспособности и надежности деятельности и т.п.

Итак, живой организм может адекватно функционировать только при наличии у него механизмов постоянного уравновешивания своих возможностей с действием на него вредных факторов трудовой среды. На популяционном уровне такие механизмы особенно рельефно выражены в регионах с экстремальными условиями обитания [1], о чем свидетельствует значительная физиологическая гетерогенность, обнаруживаемая среди здоровых людей, в этих регионах. Такая гетерогенность дает возможность популяции осуществить направленный выбор множества вариантов успешного приспособления к действию агрессивных факторов внешней среды, что, по-видимому, повышает потенциал популяции выживания в этих условиях. Для обеспечения адекватного уравновешивания со средой необходимо выполнение нескольких условий. Во-первых, нужны достаточные для осуществления работы в экстремальных условиях физиологические резервы организма. Во-вторых, механизмы пополнения этих резервов должны обеспечивать их достаточный уровень, поскольку при превалировании потребления этих резервов, то есть нарушении баланса пополнение-потребление в сторону потребления, организм не сможет обеспечить адекватную жизнестойкость в процессе преодоления действия экстремальных факторов.

Для получения нужного результата под воздействием регуляторных механизмов в организме обеспечиваются определенные реакции компенсации, способствующие гармонизации влияния внутренней и внешней среды. Интенсивность этого двуединого активно протекающего процесса отражают показатели степени напряжения различных регуляторных процессов в организме человека, наиболее популярными из которых в психофизиологии труда являются показатели напряжения механизмов функционирования ССС, в частности, показатели вариабельности сердечного ритма. Используя эти показатели для оценки уровня функциональных резервов и тенденции его изменения, можно разработать специальные медико-информационные технологии для обучения человека адекватному 
поведению в условиях действия экстремальных факторов.

Целесообразно констатировать, что поскольку человек может успешно работать в условиях повышенного уровня стресса, то именно сложные условия экстремальной деятельности являются тем системообразующим фактором, который вносит в систему «человек-техника» свойство эмерджентности и, таким образом, в определенной степени выступает как ресурс компенсации действия этого стресса. Исходя из этого положения, вероятным является такой механизм приспособления, который способствует вырабатыванию у человека специального защитного ответа, связанного с формированием в процессе осуществления профессиональной деятельности функционального по своей природе психофизиологического «панциря» с помощью создания специальной функциональной системы. Наличие такого «панциря» позволяет ему не только достичь успеха в работе, но и уменьшить влияние стресса в экстремальных условиях трудовой среды. Вероятно, построению этого «панциря» способствует «минидарвиновский» процесс естественного отбора, который приводит к быстрому удалению из зон повышенного стресса индивидуумов с недостаточным уровнем адаптации.

Для реализации защитногодействия психофизиологического «панциря» должны быть выполнены, по крайней мере, три условия. Во-первых, фундаментом осуществления защиты являются соответствующие физиологические резервы организма, отражающиеся в текущем функциональном состоянии человека. Во-вторых, человек должен иметь информацию о необходимых действиях для адекватного реагирования на возникшую экстремальную ситуацию, то есть должны быть созданы условия для функционирования механизмов антиципации. В-третьих, ведущим, во всяком случае, на начальном этапе развития экстремальной ситуа-

\section{Литература}

1. Агаджанян Н. А. Этнос, здоровье и проблемы адаптации / Н. А. Агаджанян, Г. М. Коновалова, Р. Ш. Ожева // Новые технологии. - 2010. - № 3. - С. 88-92.

2. Алещенко В. І. Психологічна реабілітація військовослужбовців з постстресовими психічними розладами / В. І. Алещенко, О. Ф. Хміляр. - Харків : ХУПС, 2005. - 84 c.

3. Ахметзянова А. И. Теоретический анализ представлений о развитии антиципирующей функции психического отражения / А. И. Ахметзянова // ции, является способность человека выделить среди существующих факторов трудовой среды тот фактор, который несет наибольшую опасность его жизни, здоровью и успешному выполнению производственного задания. В последнем случае даже кажущаяся нейтральность поступающих сообщений при развитии экстремальных ситуаций становится значимой, влекущей за собой существенное изменение устойчивости организма к стрессу. Жизнеобеспечивающие реакции организма, соответствующие имеющимся вызовам внешней среды, должны приводить к формированию адекватных ответов, способствующих стабилизации возникающих в нем изменений [32]

Важность действия таких механизмов определяется тем, что человек в процессе своей трудовой деятельности может временно попадать в такие условия, которые не соответствуют обычным обстоятельствам существования его организма. Однако наличие механизмов формирования психофизиологического «панциря» помогает человеку не только выжить, но и успешно проводить определенную работу, подвергая в этом случае свой организм повышенному риску быстрого разрушения.

\section{Выводы}

1. Проведена структуризация экстремальных факторов трудовой среды, позволяющая выделить наиболее значимые из них и определить их место в системе действующих на человека раздражителей.

2. Сформулирована гипотеза о возможном механизме «естественного отбора» под действием комплекса экстремальных факторов, позволяющем оставить на работе тех лиц, у которых возможно формирование защитного психофизиологического «панциря», способствующего их устойчивости к преодолению имеющихся испытаний.

Гуманитарные и социальные науки. - 2015. - № 3. C. 233-249.

4. Белевитин А. Б. Современные взгляды на медицинскую реабилитацию лиц опасных профессий / А. Б. Белевитин // Медицина катастроф. - 2011. № 2. - C. 14-17.

5. Беленки Г. Стресс на поле боя: опыт Израиля / Г. Беленки, Ш. Ной, З. Соломон // Милитариревью. 1985. - № 7. - С. 28-37.

6. Биккинина Г. М. Обоснование подходов к реализации превентивных мероприятий профессионально- 
обусловленной патологии у сотрудников силовых структур / Г. М. Биккинина, Л. Р. Мингазова // Сибирский медицинский журнал. - 2011. - Т. 26, Вып. 1. С. $166-170$.

7. Бодров В. А. Информационный стресс / В. А. Бодров. - Москва : ПЕР СЭ, 2000. - 352 с.

8. Бодров В. А. Психологический стресс: развитие и преодоление / В. А. Бодров.- Москва : Речь, 2006. 523 с.

9. Военная инженерная психология; под ред. В. Ф. Рубахина. - Москва : Воениздат, 1970. - 138 с.

10. Голоков В. А. О состоянии здоровья сотрудников органов внутренних дел, выполнявших служебные задачи в особых условиях Северо-Кавказского региона / В. А. Голоков, Т. Я. Николаева, С. А. Сергеев // Якутский медицинский журнал. - 2010. - № 1. C. 29-30.

11. Григорьев П. Е. Индивидуально-психологические корреляты особенностей интуитивного предсказания опасных ситуаций сотрудниками органов внутренних дел / П. Е. Григорьев, И. В. Васильева, А. Н. Игнатов // Вестник Краснодарского университета МВД России. - 2016. - № 1(31). - С. 196-201.

12. Психология экстремальных ситуаций для спасателей и пожарных / Т. Н. Гуренкова, И. Н. Елисеева, Т. Ю. Кузнецова [и др.]. - Москва : Смысл, 2007. - 319 c.

13. Дикая Л. Г. Отношение человека к неблагоприятным жизненным событиям и факторы его формирования / Л. Г. Дикая, А. В. Махнач // Психологический журнал. - 1996. - № 3. - С. 137-148.

14. Дьяченко М. И. Готовность к деятельности в напряженных ситуациях / М. И. Дьяченко, Л. А. Кандыбович, В. А. Пономаренко. - Минск : Изд-во «Университетское», 1985. - 206 с.

15. Сна Т. А. Професійно важливі якості диспетчерів енергосистем / Т. А. Єна, В. В. Кальниш // Укр. журн. з пробл. медицини праці. - 2010. - № 4 (24). - С. 11-20.

16. Зайцев Г. С. Экстремальные условия деятельности: понятие, содержание, классификации / Г. С. Зайцев // Вестник КРСУ. - 2014. - Т. 14, № 10. C. 25-29.

17. Инженерная психология в военном деле; под ред. Б. Ф. Ломова. - Москва : Воениздат, 1983.- 224 с.

18. Кальниш В. В. Монотонная деятельность и состояние монотонии. Сообщение 1. Определение и факторы формирования / В. В. Кальниш // Укр. журн. $з$ пробл. медицини праці. - 2016. - № 1 (46). C. $18-30$.

19. Кальниш В. В. Монотонная деятельность и состояние монотонии. Сообщение 2. Механизмы развития состояния монотони / В. В. Кальниш // Укр. журн. з пробл. медицини праці. - 2016. - № 2 (47). C. $33-44$.
20. Китаев-Смык Л. А. Психология стресса / Л. А. Китаев-Смык. - Москва : Наука, 1984. - 386 с.

21. Китаев-Смык Л. А. Психология стресса. Психологическая антропология стресса / Л. А. КитаевСмык. - Москва : Академический проект, 2009. - 943 с.

22. Ковальзон В. М. Цикл бодрствование-сон и биоритмы человека при различных режимах чередования светлого и темного периода суток / В. М. Ковальзон, В. Б. Дорохов // Здоровье и образование в XXI веке. - 2013. - Т. 15, № 1-4. - С. 151-162.

23. Патоэндосаногенез системной патологической реакции у пострадавших с легкой механической травмой / А. Е. Коровин, Ю. Н. Шанин, С. М. Бодань, А. В. Шулепов // Бюллетень северного государственного медицинского Университета. - 2013. - № 2. С. $40-42$.

24. Кошкаров В. С. Влияние места несения службы и стажа работы на индивидуально-личностные особенности сотрудников пожарной охраны / В. С. Кошкаров, Н. Н. Щаблов // Проблемы управления рисками в техносфере. - 2010. - № 4 (16). - С. 97-103.

25. Кузнецов А. Г. К физиологии экстремальных воздействий на организм / А. Г. Кузнецов // Экологическая физиология человека: адаптация человека к экстремальным условиям среды. - Москва : Наука, 1979. - С. 5-20.

26. Ластовченко В. Б. Особенности десинхронизации суточных биоритмов операторов при сменном графике работы / В. Б. Ластовченко // Укр. журн. 3 пробл. медицини праці. - 2011 . - № 2. - С. 3-10.

27. Лебедев В. И. Личность в экстремальных условиях / В. И. Лебедев. - Москва : Политиздат, 1989. $228 \mathrm{c}$

28. Ломов Б. Ф. Антиципация в структуре деятельности / Б. Ф. Ломов, Е. Н. Сурков / / Психологический журнал. - 1980. - Т. 1, № 6. - С. 162-165.

29. Марищук В. Л. Поведение и саморегуляция человека в условиях стресса / В. Л. Марищук, В. И. Евдокимов. - Санкт-Петербург : Сентябрь, 2001. - 260 с.

30. Марищук В. Л. Перераспределение функциональных резервов в организме спортсмена как показатель стресса / В. Л. Марищук // Стресс и тревога в спорте. - Москва : Физкультура и спорт, 1983. - С. 72-87.

31. Меерсон Ф. З. Адаптация, стресс и профилактика / Ф. З. Меерсон. - Москва : Наука, 1981. - 279 с.

32. Меницкий Н. В. Информация и проблемы высшей нервной деятельности / Н. В. Меницкий, В.В.Трубачев. - Ленинград : Медицина, 1974. - 232 с.

33. Мисюра В. Ф. Психологическая реабилитация военнослужащих / В. Ф. Мисюра. -Москва : Академия им. Фрунзе, 1995. - 25 с.

34. Михайлов Б. А. Психологические операции ВС США в конфлитах малой интенсивности / Б. А. Михайлов / / Зарубежн. воен. обзор. - 1996. - № 8. - С. 2-7. 
35. Михайлова Л. А. Гигиенические и физиологические аспекты деятельности специалистов экстремальных профессий / Л. А. Михайлов // Фундаментальные исследования. - 2014. - № 2. - С. 1626-1631.

36. Наенко Н. И. Психическая напряженность / Н. И. Наенко // Психическая напряженность. Фрустрация: Хрестоматия; сост. И. В. Герасимова.- Владивосток : МГУ, 2001.- С. 6-50.

37. Небылицын В. Д. Основные свойства нервной системы человека / В. Д. Небылицын // Избранные психологические труды. - Москва : Просвещение, 1990. - C. 25-343.

38. Носов Н. А. Виртуальная психология / Н. А. Носов. - Москва : Аграф, 2000. - 432 с.

39. Осьодло В. Діагностика, формування і розвиток психологічної готовності до професійної діяльності: методичні аспекти / В. Осьодло // Вісник Київського національного університету імені Тараса Шевченка. Військово-спеціальні науки. - 2015. - № 1 (32). C. $30-32$.

40. Пронина Г. А. Оценка изменений личностных характеристик и качества жизни, ассоциированных с метаболическим синдромом, у спасателей МЧС России / Г. А. Пронина, Е. Д. Пятибрат, С. С. Бацков // Вестник психотерапии. - 2013. - № 48 (53). - С. 52-56.

41. Психологічна енциклопедія; Автор-упорядник О. М. Степанов. - Київ : Академвидав, 2006. - 424 с.

42. Смирнов Б. А. Психология деятельности в экстремальных ситуациях / Б. А. Смирнов, Е. В. Долгополова. - Харьков : Изд-во Гуманитарный Центр, 2007. - 292 c.

43. Тімченко О. В. Синдром посттравматичних стресових порушень: концептуалізація, діагностика, корекція та прогнозування / О. В. Тімченко. - Харків : Вид-во Ун-ту внутр. справ, 2000. - 268 с.

44. Хайрулін О. Професійне вигорання військовослужбовців як предмет психологічного аналізу / О. Хайрулін // Психологія і суспільство. - 2014. - № 2. C. $98-128$.

45. Шевченко Т. И. Сравнительное исследование нервно-психической устойчивости у пожарных, горноспасателей и курсантов пожарно-спасательного колледжа / Т. И. Шевченко, Н. В. Макарова / / Медикобиологические и социально-психологические проблемы безопасности в чрезвычайных ситуациях. - 2013. № 1. - C. 74-77.

46. Bleise P. D. Age and individual variability in performance during sleep restriction / P. D. Bleise, N. J. Wesensten, T. J. Balkin // J. Sleep. Res. - 2006. № 15 (4). - P. 376-385.

47. Juda M. Chronotype Modulates Sleep Duration, Sleep Quality, and Social Jet Lag in Shift-Workers / M. Juda, C. Vetter, T. Roenneberg / / Journal of biological rhythms. - 2013. - V. 28. - № 2. - P. 141-151.

48. Kirkcaldy B. Occupational stress, work satisfaction and health among the helping processions / B. Kirkcaldy, R. J. Shephard // Eur. Rev. Appl. Psihol. - 2004. - V. 51. P. 243-253.

49. Ogdinska-Bulik N. Negative and positive effects of traumatic experiences in a group of emergency service workers - the role of personal and social resources / N. Ogdinska-Bulik // Med Pr. - 2013. - № 64 (4). P. 463-472.

50. Pek E. Health survey of ambulance workers with a generic questionnaire (SF-36) / E. Pek, I. Martai, J. Marton // Orv. Hetil. - 2013. - № 154 (47). - P. 1865-1872.

\section{Камьниш В. В. \\ ПРОФЕСІЙНА АIЯАЬНІСТЬ В ЕІКТТРЕМАМЬНИХ УМОВАХ СЕРЕАОВИША: ВИВНАЧЕНHЯ, КАAСИФIКАUI}

\section{Аержавна установа «Інститут медишини праші Нашіональної академії медичних наук України», м. Київ}

Bcmyn. Дослідження впливу екстремальних умов діяльності на здоров’я та успішність праці людини нині отримало новий імпульс, поява якого пов'язана з ускладненням техніки, виникненням нових небезпечних видів професійної діяльності, повсюдним використанням застарілого устаткування, а також багатьох інших чинників, що формують сучасні проблеми в медицині праці.

Мета дослідження - структурувати відомості про вплив на організм працівника чинників екстремальних умов середовища й встановити вірогідні підходи, що дозволяють організму компенсувати їхню шкідливу дію.

Матеріали та методи дослідження. Проведений аналіз і узагальнення даних літератури з питань впливу екстремальних умов праці на організм людини.

Результати. У результаті аналізу даних літератури запропонована класифікація умов і ситуацій, що формують стрес у людини, працюючої в умовах з підвищеною небезпекою. Запропонований підхід, у якому на основі механізму стихійного відбору здійснюється селекція осіб, здатних працювати в цих умовах шляхом формування спеціальної функціональної системи, яку можна назвати психофізіологічним «панциром».

Висновки. Проведено структуризацію екстремальних чинників трудового середовища, що дозволяє виділити найзначущіші з них і визначити їхнє місце в системі діючих на людину подразників. Сформульовано гіпотезу можливого механізму «природний відбір» під дією комплексу екстремальних чинників, що дозволяє залишити на роботі 
тих осіб, у яких можливе формування захисного психофізіологічного «панцира», сприяючого їхній стійкості до подолання наявних викликів.

Ключові слова: екстремальні умови діяльності, небезпечні умови праці, класифікація чинників середовища, психоемоційна напруга

\section{Kalnish V. V. OCCUPATIONAL ACTIVITY IN EXTREME WORIK CONDITIONS: DEFINITION AND CLASSIFICATIONS}

\section{State Institution «Institute for Occupational Health of the National Academy of Medical Sciences of Ukraine», Kyiv}

Introduction. The investigation of the effect of extreme work conditions on the state of workers' health and on successfulness of a human work has gained, at present, a new impulse. Its occurrence is explained by complications of technologies, appearance of new dangerous types of occupational activity, all-round use of the obsolete equipment as well as of many other factors, contributing to modern problems of occupational health.

Purpose of the study - to structure the data on the effect of factors of the extreme work conditions of the worker's health and to establish probable approaches, allowing the body to compensate their harmful effect.

Materials and methods. The analysis and generalization of the literature data on the problems of the effect of extreme work conditions on the human health have been conducted.

Results. Resulting from the analysis of the literature data a Classification on conditions and/or situations, forming a stress in a human, engaged in work conditions of high danger, has been proposed. An approach, based on the mechanism of the natural selection of persons, capable to work in such extreme conditions, has been established by means of formation of a special functional system, which can be named as a psychophysiological «armour».

Conclusion. The extreme factors of the work environment has bee structured, which makes it possible to distinguish the most significant of them, and, so, to define their place in the system of irritants influencing a human. A hypothesis has been stated on the probable mechanism of "natural selection" under the effect of a combination of extreme factors, enabling to permit working only such individuals, in whom the development of the defensive psychophysiological «armour» is possible, promoting their stability to overcoming the available tests.

Key words: extreme work conditions, dangerous work conditions, Classification on work environmental factors, psycho-emotional strain

\section{References}

1. Agadzhanyan, N. A., Konovalova, G. M., Ozheva, R. Sh. 2010, "Ethnos, health and problems of adaptation", Novye tekhnologii (New teechnlogies), no. 3, pp. 88-92 (in Russian).

2. Aleschenko, V. I., Khmilyar, O. F. 2005, Psychological rehabilitation of military men with post-stress psychic disorders. Kharkiv : KhUПC, 84 p. (in Ukrainian).

3. Akhmetzyanova, A. I. 2015, "Theoretical analysis of concepts on development of anticipating function of psychic reflection", Gumanitarnye i sotsialnye nauki (Humanitarisn and social sciences), no. 3, pp. 233-249 (in Russian).

4. Belevitin, A. B. 2011, "Modern views on medical rehabilitation of individuals with dangerous professions", Meditsina katastrof (Medicine of catastrophes, no. 2, pp. 14-17 (in Russian).

5. Belenki, G., Noi, Sh., Solomon, Z. 1985, "Stress on a battlefield: an Israel experience», Military review, no. 7, pp. 28-37 (in Russian).

6. Bikinina, G. M., Mingazova, L. R. 2011, "Substantiation of approaches to realization of preventive measures on work-related pathology in workers of force structures", Sibirskyj medithinskiy zhurnal (Siberea medical Journal), v. 26, Issue 1, pp. 166-170 (in Russian).
7. Bodrov, V. A. 2000, Information stress. Moscow : Per se, 352 p. (in Russian).

8. Bodrov, V. A. 2006, Psychological stress: development and overcoming. Moscow : Rech, 523 p. (in Russian).

9. Military engineering psychology. 1970, (Ed. V. F. Rubakhin). Moscow : Voyenizdat, p. 138.10 (in Russian).

10. Golokov, V. A., Nikolayeva, T. Ya., Sergeyev, S. A. 2010, "On the state of health of workers of inner affairs, solving their professional tasks in specific conditions of the Northern-Caucasss Region", Yakutsk med. J., no 1, pp. 29-30 (in Russian).

11. Grigoryev, P. E., Vasilyeva, I .V., Ignatov, A. N. 2016 , "Individual-psychological correlates of peculiarities of intuitive prediction of dangerous situations in employees of internal affairs", Vestnik of Krasnodar Univ., no. 1 (31), pp. 196-201 (in Russian).

12. Gurenkova, T. N., Eliseyeva, I. N., Kuznetsova, T. Yu. et. al. 2007, Psychology of extreme situations for rescuers and firefighters. Moscow : Smysl, 319 p. (in Russian).

13. Dikaya, L. G., Makhnach, A. V. 1996, "The attitude of a person to unfavorable life events and factors of his/ her formation", Psikhologicheskyi zhurnal, no. 3, pp. 137148 (in Russian). 
14. Dyachenko, M. I., Kandybovich, L. A., Ponomarenko, V. A. 1985, Readiness for activity in stressful situations. Minsk: University publishing, 206 p. (in Russian).

15. Yena, T. A., Kalnysh, V. V. 2010, "Professionally important qualities of power systems' dispatchers", Ukr. J. Occup. Health, no. 4 (24), pp. 11-20 (in Ukrainian).

16. Zaitsev, G. S. 2014, "Extreme conditions in activity: concept, content, classifications", Vestnik KRSU, v. 14, no. 10, pp. 25-29 (in Russian).

17. Engineering psychology in military affairs. 1983, (Ed. B.F. Lomov). Moscow : Voyenizdat, 224 p. (in Russian).

18. Kalnish, V. V. 2016, "Monotone activity and the state of monotonia. Information 1. Definition and factors of formation", Ukr. J. Occup. Health, no. 1 (46), pp. 18-30 (in Russian).

19. Kalnish, V. V. 2016, "Monotone activity and the state of monotonia. Information 2. Mechanisms of development of the monotonia state», Ukr. J. Occup. Hralth, no. 2 (47), pp. 33-44 (in Russian).

20. Kutayev-Smyk, L. A. 1984, Stress psychology. Moscow : Nauka, 386 p. (in Russian).

21. Kitayev-Smyk, L. A. 2009, Stress psychology. Psychological stress anthropology. Moscow : Акаdemicheskyi proekt, 943 p. (in Russian).

22. Kovalson, V. M., Dorokhov, V. B. 2013, "The wakefulness-sleep cycle and human biorhythms under different alternating conditions of light and dark period of the day", Zdorovye i obrazovaniye v XXI st., v. 15, no. 1-4, pp. 151-162 (in Russian).

23. Korovin, A. E., Shanin, Yu. N., Bodan, S. M., Shulepov, A. V. 2013, "Pathoendosanogenesis of systemic pathological reaction in victims with slight mechanical trauma", Bull. North Med. Univ., no. 2, pp. 40-42 (in Russian).

24. Kosharov, V. S., Schablov, N. N. 2010, "Influence of the place of service and work experience on the individual and personal characteristics of workers of the fire department" Problems of risk management in the technosphere, no. 4 (16), pp. 97-103 (in Russian).

25. Kuznetsov, A. G. 1969, To the physiology of extreme environment effects on the human body. Moscow : Nauka, pp. 5-20 (in Russian).

26. Lastovchenko, V. B. 2011, «Peculiarities of desynchronization of daily biorhythms in operators with changing work schedules», Ukr. J. Occup. Health, no. 2, pp. 3-10 (in Russian).

27. Lebedev, V. I. 1989, Personality under extreme conditions. Moscow : Politizdat, 228 p. (in Russian).

28. Lomov, B. F., Surkov, E. N. 1980, Anticipation in the structure of activity, "Psykhologicheskyi zhurnal", v. 1, no. 6, pp. 162-165 (in Russian).
29. Marischuk, V. L., Yevdokimov, V. I. 2001, Human behavior and self-regulation in stress conditions, SanktPeter., 260 p. (in Russian).

30. Marischuk, V. L. 1983, Redistribution of functional reserves in the body of an athlete as a stress indicator, Stress and anxiety in sports. Moscow : Fuzkultura i sport, pp. 72-87 (in Russian).

31. Meerson, F. Z. 1981, Adaptation, stress and prevention. Moscow : Nauka, 279 p. (in Russian).

32. Menitsk, N. V., Trubachev, V. V. 1974, Information and problems of higher nervous activity. Leningrad : Meditsina, 232 p. (in Russian).

33. Misyura, V. F. 1995, Psychological rehabilitation of servicemen. Moscow : Frunze Academy, 25 p. (in Russian).

34. Mikhailov, B. A. 1996, "Psychological operations of USA military forces in conflict situations of low intensity", Foreign military overviews, no. 8, pp. 2-7 (in Russian).

35. Mikhailova, L. A. 2014, "Hygienic and physiological aspects of activity in specialists of extreme professions", Fundamental studies, no. 2, pp. 1626-1631 (in Russian).

36. Nауепко, N. I. 2001, Psychological tension. Frustration. Reader (Ed. I. V. Gerasimov). Vladivostok : MGU, pp. 6-50 (in Russian).

37. Nebylitsyn, V. L. 1990, "Main properties of the human higher nervous system", Selected psychological works. Moscow : Prosvesheniye, pp. 5-343 (in Russian).

38. Nosov, N. A. 2000, Virtual psychology. Moscow : Agraf, 432 p. (in Russian).

39. Osyodlo, V. 2015, "Diagnostics, formation and development of psychological readiness for professional activity: methodical aspects", Visnyk of Kyiv Taras Shevchenko University, Military-special sciences, no. 1 (32), pp. 30-32 (in Ukrainian).

40. Pronina, G. A., Pyatibrat, E. D., Batskov. S. S. 2013, "Assessment of changes in personality characteristics and quality of life associated with the metabolic syndrome in rescuers of the Ministry of extreme situations in Russia», Vestnik psykhoterapii, no. 48 (53), pp. 52-56 (in Russian).

41. Stepanov, O. M. 2006, Psychological encyclopedia. Kyiv : Aкademvydav, 424p. (in Ukrainian).

42. Smirnov, B. A., Dolgopolova, E. V. 2007, Psychology of activity in extreme situations. Kharkov : Gumanitarnyi Tsentr, 292 p.(in Russian).

43. Timchenko, O. V. 2000, The syndrome of posttraumatic stress disorders: conceptualization, diagnosis, correction and prognosis. Kharkiv : Publishing of the University of Internal Affairs, 268 p.(in Ukrainian).

44. Khairulin, O. 2014, "Professional burnout of servicemen as a subject of psychological analysis", Psikhologia i suspilstvo, no. 2, pp. 98-128 (in Ukrainian).

45. Shevchenko, T. I., Макаrova, N. V. 2013, Comparative study of neuromuscular resistance in firefighters, 
mine rescuers and students of the fire and rescue college, Medico-biological and socio-psychological problems of safety in emergency situations, no. 1, pp. 74-77 (in Russian).

46. Bleise, P. D., Wesensten, N. J., Balkin, T. J. 2006, "Age and individual variability in performance during sleep restriction", J. Sleep. Res., no. 15 (4), pp. 376-385.

47. Juda, M., Vetter, C., Roenneberg, T. 2013, "Chronotype Modulates Sleep Duration, Sleep Quality, and Social Jet Lag in Shift-Workers", Journal of biological rhythms, v. 28, no. 2, pp. 141-151.

Поступила: 3 января 2017 г.
48. Kirkcaldy, B., Shephard, R. J. 2004, "Occupational stress, work satisfaction and health among the helping processions», Eur. Rev. Appl. Psychol.,v. 51, pp. 243-253.

49. Ogdinska-Bulik, N. 2013, "Negative and positive effects of traumatic experiences in a group of emergency service workers - the role of personal and social resources", Med Pr., no. 64(4), pp. 463-472.

50. Pek, E., Martai, I., Marton, J. 2013, «Health survey of ambulance workers with a generic questionnaire (SF36)», Orv. Hetil., no. 154 (47), pp. 1865-1872.

Контактное лицо: Кальниш В. В., лаборатория психофизиологии труда, ГУ «Институт медицины труда НАМН Украины», д. 75, ул. Саксаганского, г. Киев, 01033. Тел.: + 380442843427. 